\title{
Materials Research Spokesgroup Dialogue
}

On the morning of April 17, 1986 a group of 25 prominent materials researchers met in Palo Alto, California to further examine the validity of a materials research "spokesgroup" in the context of a broad group of materials constituencies. This conclave grew out of a December 1985 "Materials Research Facilities Dialogue" (see the BULLETIN Vol. XI, No. 1, p. 41). Attendees at that dialogue agreed that no effective and representative spokesgroup for materials research existed, perceiving two major consequences: a failure in showing government the importance of materials research and development to national needs and goals, and a tendency for the materials community to squabble publicly over priorities, leaving policymakers with no clear mandate. The latter problem has been echoed by many, including the President's former science advisor, George A. Keyworth, and Alvin Trivelpiece of DOE (see "Annual Spring Forum Held at NAS" in this issue).

Robb Thomson (NBS), Paul Holloway (University of Florida), and Elton Kaufmann (Lawrence Livermore National Laboratory) tackled the task of identifying individuals from as wide a variety of materials constituencies as possible. They contacted some 28 technical societies, ${ }^{*}$ asking these societies to suggest participants who reflected their materials research interests. It was emphasized that the resulting 25 attendees ${ }^{* *}$ would not be regarded as official representatives of the societies that identified them and that the gathering itself, which made use of MRS Spring Meeting facilities, was not an official MRS function.

Though this group was far more diverse than the one that gathered in December, the consensus here was also that no single broadly representative spokesgroup for materials research exists. But, the agreement went beyond that to the realization that no clear and simple route to the creation of such a group could be identified. The interests and priorities of the far-flung fields of materials science and engineering are simply too disparate for a single entity to speak authoritatively for the community as a whole.

In arriving at this conclusion, the attendees discussed a variety of existing bodies which already play spokesgroup roles. Included were the confederations of societies such as the Federation of Materials Societies (see "Report on FMS Workshop on Electronic Materials" in this issue), American Association of Engineering Societies, American Institute of Physics, American Institute of Mining and Metallurgical Engineers, and more. Also discussed were the large number of boards and committees of the National
Academies, the advisory groups created by funding agencies, and a plethora of ad hor working and study groups that arise for specific issues. It was generally agreed that these groups often function well as honest brokers for their particular constituencies or as study teams on topics of limited scope. However, it was also pointed out that of ten members of these groups are chosen without input from individual scientists from the materials community, and that the community at large perceives itself as generally uninformed about the activities of these groups and unrepresented in them.

Several other observations by individual participants are worth noting:

1. The technical societies have grown up as distinct organizations covering specific areas as a result of technical (as opposed to political) needs. Therefore, these societies have self-defined interests, organizational structures, and restrictions which render them less effective (as a group) in providing government with answers to materialsrelated questions as they arise. Related to this is the explicit stricture against lobbying by tax-exempt nonprofit societies. Also, for a membership organization with constitutionally elected governors to express

an official posture usually requires a cumbersome review and decision process that is inconsistent with timely response to government inquiries.

2. For existing multisociety groups to function effectively, individual constituent societies must actively participate, providing and receiving timely information relevant to individual researchers' needs and ongoing government deliberations.

3 . There is certainly a need for more effective ways to communicate the importance of materials research to government. A corollary to this, however, is that effective in teraction with government requires considerable familiarity with how the "system" works and where the real opportunities exist to influence policy. Not "knowing the ropes" may be not only ineffective but counterproductive

4. Even though an official umbrella organization seems to be infeasible for the reasons mentioned, informal cooperation among all the technical societies is not precluded. Without the onus of speaking officially for any group, such a cooperative could act as conduit for open information flow between government and the several continued

\section{MSE Study Invites Input from Societies}

During the lunch hour on April 17, the participants from the "spokesgroup" dialogue were treated to a description of the organization, status, and plans of the new "Materials Science and Engineering Study" being conducted by the National Research Council for the National Academies of Sciences and Engineering. The presentation was made by Praveen Chaudhari of IBM who, with Merton Flemings of MIT, co-chairs the Study. This presentation was particularly apropos because the underlying need for such a study is related to the same lack of unified input to government by the materials community that spawned that morning's meeting. The structure of the Study is similar to that described in the January/February issue of the MRS BULLETIN (Vol. XI, No. 1, p. 63) with the addition of names of chairs and co-chairs of the five Study panels. (These names are listed in "Annual Spring Forum Held at NAS" in this issue.) Chaudhari described an ambitious schedule to have a draft report of the Study ready in one year. The Study, through use of extensive source citation, would be limited to about one hundred pages. One source is, explicitly, input from the materials community at large.
Flemings have written to the presidents of materials-related technical societies.
They invited the societies to identify an individual to act as a liaison between the Study and the society and to supply to the Study any statistical demographic and support data that they might have available or might gather. Beyond that, the Study co-chairs invited societies to utilize their own meeting formats to produce input for the Study. They also offered those societies which have forums in the Fall, when the Study is expected to present progress reports, an opportunity to provide feedback at that intermediate stage.

These explicit overtures to the societies to provide input were warmly received by Chaudhari's audience. The degree to which this opportunity is utilized is now up to the individual
societies. This is an excellentopportunity for societies to contribute substantively to the Study. The Materials Research Society is responding by providing the opportunity to contribute written input to the Study through a "communications" book and the opportunity to
attend a "forum" on the Study at the Society's Fall Meeting in Boston. "MRS Respon 
constituencies. This approach is probably also consistent with the mission of all technical societies: enhancing opportunities for communicating information on the technical pursuits of their memberships. Government policies and actions a re clearly relevant to those pursuits.

5. In general, it is not the nature of the U.S. government to spontaneously request information from the societies, nor to offer briefings on government activities. Where such interactions have occurred, they have arisen from a concerted effort on the part of some organized subgroup of the research community to deliver a particular message on one hand, and through the conscientious gathering of government activity news by a few science writers and Washington, DC outposts of the societies.

The most straightforward aspect of the information exchange proposition seemed to be one in which representatives of the various constituencies (chosen as for this April 17 meeting with the help of the societies) meet informally in Washington, DC to be briefed by officials of, for example, the agencies and the Academies. The general content of the briefing could then be disseminated via the usual mechanisms within the societies, such as newsletters and the like. This notion of a "top-down" briefing is being carried back by the participants to their constituencies to gauge the interest in such an arrangement. If sufficient interest is shown, an event of this type may be arranged next year.

Less obvious was a means to facilitate the "bottom-up" information flow in a constructive, albeit unofficial, way. Although it was clear that each technical society is able to poll it $\mathrm{m}$ - mbers on specific issues and that society leaders are naturally well informed and sensitive to the concerns of their members, this group proposed no specific mechanism to provide informal advice to government representatives on "grassroots" concerns. Some expressed the expectation that if a briefing-style meeting could be arranged, natural avenues and opportunities would develop for upward transmission in that context.

Participants adjourned for lunch where, in addition to continuing the morning's discussions, a presentation was graciously offered by Praveen Chaudhari (IBM), who co-chairs the new Materials Science and Engineering Study of the National Academies.

* The societies contacted and responding positively were:

Acoustical Society of America

American Association of Crystal Growth

American Ceramic Society

American Chemical Society

American Crystallographic Association

American Geophysical Union

American Institute of Chemical Engineers

American Nuclear Society

American Physical Society

American Society for Metals

American Society of Mechanical Engineers

American Vacuum Society
Electrochemical Society

Electron Microscopy Society of America

Electronic Materials Committee of AIME

Institute of Electrical and Electronic Engineers

Materials Research Society

Microprobe Analysis Society

Mineralogical Society of America

National Association of Corrosion Engineers

Optical Society of America

Society of Photo-optical Instrumentation Engineers

Society of Rheology

The Metallurgical Society

University Materials Council

**Attendees were:

Martyn Adamson (Lawrence Livermore National Laboratory)

Orson Anderson (University of California-Los Angeles)

Leonid Azaroff (University of Connecticut)

Gordon Brown, Jr. (Stanford University)

Praveen Chaudhari (IBM)

Bruce Deal (Fairchild)

Rod Ewing (University of New Mexico)

Patrick Gallagher (AT\&T Bell Laboratories)

Anthony Gentile (Hughes Research Company)

James Harris (Stanford University)

Linn Hobbs (Massachusetts Institute of Technology) Richard Hoffman (Case Western Reserve University) Joseph Houston, Jr. (Houston Research Associates)

Elton Kaufmann (Lawrence Livermore National Laboratory)

Stanley Margolin (Network Consulting, Inc.)

Neil Paton (Rockwell International)

Joseph Payer (Case Western Reserve University)

Gordon Pike (Sandia National Laboratories)

C. Sheldon Roberts (Consultant)

Vincent Salmon (Consultant)

Ronald Streit (Lawtence Livermore National Laboratory)

Robert Sundahl (Signal Research Center)

Robb Thomson (National Bureau of Standards)

C. W. White (Oak Ridge National Laboratory)

Fred Young, Jr. (Oak Ridge National Laboratory)

\section{MRS \\ Corporate Participation Program}

As a Corporate Affiliate of the Materials Research Society, your organization is kept abreast of the Society's goals and activities and afforded special opportunities to enhance your research programs through:

- Subscription to MRS BULLETIN

- Advance notification of meeting programs and events

- Discounts on symposia proceedings

- Free employment ad placement in MRS BULLETIN

And more.

For complete details on the program, contact: Julia Phillips

AT\&T Bell Laboratories

(201) $582-4428$ or

MRS Headquarters,

9800 McKnight Road, Suite 327

Pittsburgh, PA 15237

(412) $367-3003$
MRC says: "Get your quote from ESPI...

\section{for high purity foils, powders and fine non-precious wires $\left(<.020^{\prime \prime}\right)$."}

ESPI has acquired the Materials Research Corporation inventory of high purity foils, powders and fine wires. MRC will no longer quote on these items and is now referring all inquiries to ESPI.

With over 5000 high purity items and 35years of service and dependability, ESPI more than ever, is your prime source for both research and production high purity materials.

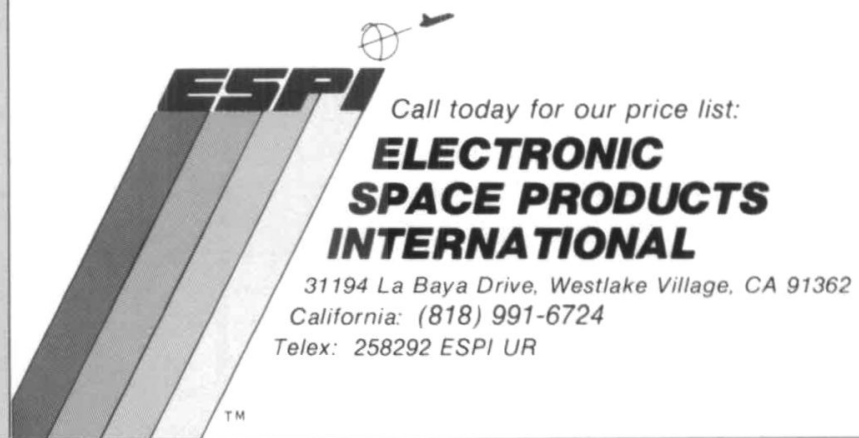

